\title{
Higher education: issues, challenges and suggestions
}

\author{
${ }^{1}$ Dr. Simmi Vashishtha, ${ }^{2}$ Kamaljit Singh \\ ${ }^{1}$ Assistant Professor, University School of Management, Kurukshetra University Kurukshetra, \\ Haryana, India, ${ }^{2}$ Research scholar, University School of Management, Kurukshetra University \\ Kurukshetra, Haryana, India \\ Email:. ${ }^{1}$ Simmiarora@kuk.ac.in, ${ }^{2}$ kamaljitsehjanusm17@kuk.ac.in
}

\begin{abstract}
This paper introduces the notion of holistic education into the context of higher education ecosystems. The study intends to conceptualize the theme and list out issues and challenges present education system faces with intent to connect with a wider set of teaching and learning paradigms to upgrade the capabilities of higher education eco-systems. Study recommends the need of combining experiential based learning (EBL). The study also recommends the changes needed to be adopted at this time in higher education viz.
\end{abstract}

Keywords: holistic education, teaching and learning paradigms, combining experiential based learning, pedagogy

\section{INTRODUCTION}

\subsection{Present Education system:}

In order to promote economic and industrial development in a country, the essential requirement is the capacity to develop skilled manpower of good quality in adequate number. It is pertinent to mention here that at the beginning of India's independence, there were 20 universities and 591 colleges while student's enrolment at the tertiary level of education was 0.2 million. After independence, the growth has been very impressive. India now possesses a highly developed higher education system that offers facility of education and training in almost all aspects of human creation and intellectual endeavours. India's higher education system is the third largest in the world after China and United States in terms of enrolment. India educates approximately 11 per cent of its youth in higher education as compared to 20 per cent in China. The education commission set up in 1964 under the chairmanship of Dr. D.S. Kothari (Kothari Commission) had recommended that government should spend at least $6 \%$ of its gross domestic product (GDP) on education. However, in over 50 years, we have been able to achieve only half the target. The Knowledge Commission additionally recommends an increase of at least $1.5 \%$ of GDP for higher education out of a total of at least $6 \%$ of GDP for education overall. The main governing body at the tertiary level is the University Grants Commission (India), which enforces its standards, advises the government, and helps coordinate between the centre and the state. Universities and its constituent colleges are the main institutes of higher education in India. The prospects and development in the higher education sector in India needs a critical examination in a rapidly globalising world. Expansion, inclusion and excellence were the three objectives of higher education policy of Government of India. The government had taken many steps to increase student enrolment in higher education and quality improvement in higher educational institutions. Keeping in view The Government has constituted a Knowledge Commission to suggest measures to alleviate the problems that higher education sector is afflicted with and make India a Knowledge super power in the global economy.

\section{REVIEW OF THE LITERATURE}

David Kember at. al (2007) reported that graduates required kind of comprehensive skills needed for permanent learning. The objective of this study was to examine the process for its evolution. The structural equation model (SEM) was used to test the hypothetical model with 1756 students in a university in Hong Kong. To triangulate against this model and to characterize the learning environment 
more fully, interviews were conducted with focus groups with 5-6 students from three programs with good capacity development records. The investigation of the interview data constructed a series of categories, which described the learning environment accordant with the SEM model. The learning environment that sound favourable with capacity building focused to understand the crucial notion through various evaluation methods and dynamic participation in learning activities. Teacher-student associations flourished through interaction, feedback and assistance. The advancement of associations between colleagues and students has led to an exorbitant level of collaborative learning. The authors concluded that the capacity to work with others is important and interpersonal and communication skills are crucial.

Srikanthan and Dalrymple (2005) developed an implementation approach for a quality holistic model in higher education. The methodology followed the Senge model to implement learning in organizations. According to Senge, actual learning task takes place within a "deep learning cycle". The comprehensive nature of the movement to start the learning cycle is: "guiding ideas", which render a feeling of cause; "Theory, methods and tools" to permit mankind to grasp up to date expertise; "Infrastructure innovations" to provide mankind the chance to chase their insight. The activities were considered from the stance of the holistic model. The series of theoretical constructions were investigated to understand the appropriate tools. Infrastructure process were also determined to provide people with the resources they required to develop up to date expertise.

Svensson at. al. (2017) introduced the notion of holistic education in the context of action-based corporate training, so to establish a system to reach and understand Integral evolution of the person. The goal of the system is to link with a larger set of teaching and learning paradigms as a basis for designing and evaluating instructions, to merge some of the apparent fragmentation in conceptual system for entrepreneurial education. To promote this multi-faceted view of teaching and learning, author presented a structure of Transmissive, transactional and transformative teaching methods. Author argued that all modalities are necessary for achieving and understanding the development of the whole person and that the teaching of entrepreneurship should designed to offer a reservoir of affluent and varied experiences in authentic learning environment. The three teaching methods were analysed and discussed in relation to a leadership course assignment and eight selected quotations from student deliveries in 2007 . The selected citations illustrate how transmissive, transactional, and transformative teaching. The modalities can be contextualized in the corporate training based on the action and point to it. Significant learning emerged through the integration of different teaching methods. The wealth of quotes indicates that action-based business education is a vehicle for a wide variety of learning outcomes. Consequently, the picture introduced seems to support promise as a basis to reach and understand the learning of the person in this context. The practical aspects of teaching are addressed, both around the design of authentic learning environments, as well as around the design and examination of more tangible deliveries of students in such environments.

Singh (2011) reviewed that there has been threat to higher education in the past, more contemporary calls for revolutionize can bring about a crucial change in higher education. This change occurred as an explicit response to requests for clarity and responsibility, but because of the opportunity to reflect on the purpose of higher education, the role of colleges and universities in the new millennium and emerging scientific research on how people learned these contrasting literatures were not related in a similar way. Author examined the impact of fundamental change from the political level to the institutional level and to the daily life of college and university administrators, professors and students and also we need people with higher education, who are experts and who can boost our economy. When India can impart qualified people to the rest of the world, so we can move our country from a developing nation to one nation developed very easily and quickly

Gupta and Gupta (2012) presented the current scenario of higher education in India through the analysis of different data and pinpoint the main challenges for the Indian higher education sector. This paper also presented the main initiatives and recommendations of the government to address these challenges.

\section{RESEARCH METHODOLOGY}


The study focuses on the teaching mechanisms that can be adopted to enhance teacher effectiveness and student involvement. The question arises then that how should teachers educate. What is it they ask for and what is it they examine and ultimately grade? Little coherent received wisdom helps to answer these central questions. The purpose of paper is therefore to introduce a framework with connections to multiple teaching and learning paradigms, recognizing that holistic learning is a new driver for learning outcomes.

\section{MEASURES TO BE TAKEN FOR RADICAL CHANGE}

\subsection{Experiential Learning Theory (ELT):}

Experiential learning theory offers a dynamic theory based on a learning cycle driven by the resolution of the dual dialectics of action/reflection and experience/abstraction. These two dimensions define a holistic learning space wherein learning transactions take place between individuals and the environment. The learning space is multi-level and can describe learning and development in commensurate ways at the level of the individual, the group, and the organization. ELT integrates the works of the foundational experiential learning scholars around six propositions which they all share:

(1) Learning is best conceived as a process, not in terms of outcomes.

To improve learning in higher education, the primary focus should be on engaging students in a process that best enhances their learning - a process that includes feedback on the effectiveness of their learning efforts: '... education must be conceived as a continuing reconstruction of experience .... the process and goal of education are one and the same thing.' (Dewey 1897: 79)

(2) All learning is re-learning.

Learning is best facilitated by a process that draws out the students' beliefs and ideas about a topic so that they can be examined, tested, and integrated with new, more refined ideas.

(3) Learning requires the resolution of conflicts between dialectically opposed modes of adaptation to the world.

Conflict, differences, and disagreement are what drive the learning process. In the process of learning one is called upon to move back and forth between opposing modes of reflection and action and feeling and thinking.

(4) Learning is a holistic process of adaptation.

It is not just the result of cognition but involves the integrated functioning of the total person thinking, feeling, perceiving, and behaving. It encompasses other specialized models of adaptation from the scientific method to problems solving, decision making and creativity.

(5) Learning results from synergetic transactions between the person and the environment.

Stable and enduring patterns of human learning arise from consistent patterns of transaction between the individual and his or her environment. The way we process the possibilities of each new experience determines the range of choices and decisions we see. The choices and decisions we make to some extent determine the events we live through, and these events influence our future choices. Thus, people create themselves through the choice of actual occasions they live through.

(6) Learning is the process of creating knowledge.

ELT proposes a constructivist theory of learning whereby social knowledge is created and recreated in the personal knowledge of the learner. This stands in contrast to the 'transmission' model on which much current educational practice is based where pre-existing fixed ideas are transmitted to the learner.

\subsection{Technology:}

In the present era, soft infrastructure is weighed more in comparison to hard infrastructure. There is reduction in shelf life of skillset, so it is needed that one" (student) must update oneself in order to remain relevant in the job market. Reskilling workforce is needed as there is compounding effect is going digital. It is to be ensured that our existing education seekers are skilful and flexible to reskill, in the light of present technological upgradation like Robotic process automation, AI, Virtual reality, IOT, big data analytics, cloud computing and 3D printing. Online education platforms have increased the education reach differently. An initiative by Govt. of India, the Telecom Dept. is funding 5G Technology Test-Bed that will be anchored out of IIT, Madras and whose rollout could be expected in 2020, in line with global rollouts. But technology has to be used as a means of development and destruction. 


\subsection{Societal maturity /immaturity:}

Although men and women are constitutionally at par but Indian mindset pertains to patriarchal society and females usually caught up in $3 \mathrm{Ms}$ and along with that economy is going through/facing societal immature behaviour which further crops the issues like gender inequality, glass ceiling. 3M i.e. marriage, maternity and motherhood disrupts women careers at the initial stage.

\subsection{Quality education:}

Quantity and quality of highly specialized human resources determine their competence in the global market. According to a recent government report two-third of India's colleges and universities are below standard. Real Education involves all aspects of the educational procedures with an eye to help students grow in curiosity, attentiveness, open-mindedness, intellectual thoroughness and intellectual courage. Our primary, secondary and higher education systems are not producing employable output. Our schools are widely criticized by new-age adherents for being a 'factory', churning out hundreds of doctors and engineers. It is the need of hour, therefore to impart education that must aim at offering holistic way of education; as the real purpose of the education is to replace the close mind with an open one. However, recent reforms-demonetization, GST, RERA, Bankruptcy Act, shell company evisceration, ease of doing business, UPI, Digital India, MUDRA Scheme etc. re- inforce each other to create a practical eco-system for higher education .

\subsection{Teacher Student relationship:}

Teacher-student relationship promotes a sense of familiarity and motivate students to participate in collaboration. Teacher student association allow teachers to handle the students in the same way, regardless of their background. A student who has positive and supportive association with teachers will achieve high levels of success as compared to those who have not good interaction and relationship with their teachers. Positive relationships help students learn and upgrade their passion to learn.

\subsection{Teaching Pedagogy:}

Teaching pedagogy means how teachers and students interact and the instructional approaches are executed in the classrooms. There are two approaches, which seem contradictory but they complement each other for realizing the educational goal. The two approaches are teachers-centred pedagogy and learner-centred pedagogy. learners-centred pedagogy has focus on the previous/ former knowledge and new experience for creating knowledge. It is imperative to use a suitable pedagogical approach that leads to educational success or progress, obtainment of technical skills and ability to contribute to society.

\subsection{Assessment and Feedback of facilitators:}

A good facilitator should be more learners centred without creating chaos in the classroom. For a good facilitator one should make learners aware, find out the aim of the learners, and indulge students in making some decisions in addition to be a good observer and listener.

\section{SUGGESTIONS FOR IMPROVING QUALITY OF HIGHER EDUCATION}

There are some suggestions and Expectations from Government, Industry and Educational Institutions.

1.Towards a Learning Society- As we move towards a learning society, every human activity will require contributions from experts, and this will place the entire sector of higher education in sharp focus. Although the priorities, which are being assigned today to the task of Education for All, will continue to be preponderant, the country will have to prepare itself to invest more and more on higher education and, simultaneously, measures will have to be taken to refine, diversify and upgrade higher education and research programmes.

2.Industry and Academia Connection- Industry and Academia connect necessary to ensure curriculum and skills in line with requirements. Skill building is really very crucial to ensure employability of academia to understand and make sure good jobs (keeping in view knowledge + skills + global professional skills $=$ good jobs).

3.Incentives to Teachers and Researchers- Industry and students are expecting specialized courses to be offered so that they get the latest and best in education and they are also industry ready and employable. Vocational and Diploma courses need to be made more attractive to facilitate specialized programs being offered to students. Incentives should be provided to teachers and researchers to make these professions more attractive for the younger generation. 
4.Innovative Practices- The new technologies offer vast opportunities for progress in all walks of life. It offers opportunities for economic growth, improved health, better service delivery, improved learning and socio-cultural advances. Though efforts are required to improve the country's innovative capacity, yet the efforts should be to build on the existing strengths in light of new understanding of the research- innovation-growth linkage.

5.To mobilize resources- The decline in public funding in the last two plan periods has resulted in serious effects on standards due to increasing costs on non-salary items and emoluments of staff, on the one hand, and declining resources, on the other. Effective measures will have to be adopted to mobilize resources for higher education. There is also a need to relate the fee structure to the student's capacity to pay for the cost. So that, students at lower economic levels can be given highly subsidised and fully subsidised education.

6.Student-Centred Education and Dynamic Methods- Methods of higher education also must be appropriate to the needs of learning to learn, learning to do, learning to be and learning to become. Student-centred education and employment of dynamic methods of education will require from teachers new attitudes and new skills. Methods of teaching through lectures will have to subordinate to the methods that will lay stress on self-study, personal consultation between teachers and pupils, and dynamic sessions of seminars and workshops. Methods of distance education will have to be employed on a vast scale.

7.Public Private Partnership- PPP is most essential to bring in quality in the higher education system. Governments can ensure PPP through an appropriate policy. University Grants Commission and Ministry of HRD should play a major role in developing a purposeful interface between the Universities, Industries and National Research Laboratories (NRLs) as a step towards PPP. Funding to NRLs by the government should ensure the involvement of institutions of higher education engaged in research activities to facilitate availability of latest sophisticated equipment. There has been some effort both by the government and the private education institutions to develop the teaching staff at various levels. However, this needs to be intensified with appropriate attention to all the aspects related in order to prepare quality and sufficient number of educational staff. Such efforts need a very serious structuring for the research base institutions. We have to be optimistic that private-public partnership and the Industry interface will take place in the field of education at all levels, and particularly in the backward regions, which is the need of the hour. To achieve excellence, we thus need to create a real partnership between government, educators and industry- Partnerships that can provide our high-tech industries with skilled workers who meet the standards of their industry.

8.To Provide Need Based Job-Oriented Courses- All round development of personality is the purpose of education. But the present day education is neither imparting true knowledge of life and nor improving the talent of a student by which one can achieve laurels in the field one is interested. So, combination of arts subjects and computer science and science and humanities or literature should be introduced so that such courses could be useful for the students to do jobs after recruitment in some companies which would reduce unnecessary rush to higher education. The programme must be focused on graduate studies and research and developing strategies and mechanisms for the rapid and efficient transfer of knowledge and for its application to specific national and local conditions and needs. Meritorious doctoral students should be recognized through teaching assistantships with stipends over and above the research fellowships. Finally, based on knowledge only vision of the future life and work can be had; based on this vision only a broad ambition can be fixed for oneself; and based on this ambition only one can lead interesting life doing satisfying job to do remarkable achievements in some field in the world.

9.International Cooperation- Universities in India have been a primary conduit for the advancement and transmission of knowledge through traditional functions such as research, innovation, teaching, human resource development, and continuing education. International cooperation is gaining importance as yet another function. With the increased development of transport and communication, the global village is witnessing a growing emphasis on international cooperation and action to find satisfactory solutions to problems that have global dimensions and higher education is one of them.

10.Towards a New vision- India realizes, like other nations of the world, that humanity stands today at the head of a new age of a large synthesis of knowledge, and that the East and the West have to 
collaborate in bringing about concerted action for universal upliftment, and lasting peace and unity. In this new age, great cultural achievements of the past have to be recovered and enriched in the context of the contemporary advancement so that humanity can successfully meet the evolutionary and revolutionary challenges and bring about a new type of humanity and society marked by integrated powers of physical, emotional, dynamic, intellectual, ethical, aesthetic and spiritual potentialities.

11. Cross Culture Programmes- After education, tour to all the places in India and world as far as possible with the cooperation of government is necessary so that one can understand about people, culture, arts, literature, religions, technological developments and progress of human society in the world.

12.Action Plan for Improving Quality- Academic and administrative audit should be conducted once in three years in colleges by external experts for ensuring quality in all aspects of academic activities. The self-finance colleges should come forward for accreditation and fulfil the requirements of accreditation. Universities and colleges should realise the need for quality education and come forward with action plan for improving quality in higher educational institutions.

13.Individuality- The life of one will not be interesting but rather boring, monotonous, and frustrating. This is mainly due to parental interference in the education of the children. Parental guidance is necessary but it should not interfere in the creativity or individuality of the students. Also, in spite of the obsolete type of education system, some are achieving wonderful things in Sports, Music, Dance, Painting, Science and Technology in the world. This is only due to the encouragement of the parents and some dedicated teachers in the educational institutions. Higher education is necessary for one to achieve excellence in the line one is best. But one should be selected for higher education on the basis of merit only. Further, fees for education in general should not be high; especially, the fees for higher studies should be within the reach of every class of people in the nation.

14.Fair Quality Assurance System- Colleges and Private institutes should set up Internal Quality Assurance Cell and must follow a minimum standard to give degrees. The quality assurance system must be independent of political and institutional interaction and it must have a basis in the legislation. There should be operational, financial and academic autonomy coupled with accountability. There is a need of an independent accreditation agency with a conglomerate of government, industry, academia, society etc. means all stakeholders of the education to ensure that the stakeholders particularly the students are not taken for a ride. They should be able to know whether a particular institution delivers value or not, then things can be under control to some extent. It is also important that all institutes of higher learning must make public the acceptability of their courses and degrees. (i.e. the status, recognition, and acceptability of their courses by other institutions).

\section{CONCLUSION}

Today, Knowledge is power. The more knowledge one has, the more empowered one is. The paper presented the framework reflecting the importance of holistic education in the higher education so as to make the workforce employable. Paper also focused on the effectiveness and involvement, teaching pedagogy of facilitators, assessment and feedback so as to justify the term demographic dividend. It is the high time to inculcate the reforms and bring radical changes otherwise there is a threat to our youngsters being converting into demographic liability.

\section{REFERENCES}

[1] Hartog, P. (1939). Some aspects of India education past and present: Being three JOSEPH PAYNE LECTURES for 1935-6 delivered in the Institute (with supplementary Memoranda). Oxford University Press, London.

[2] Kolb, A. Y., \& Kolb, D. A. (2009). Experiential learning theory: A dynamic, holistic approach to management learning, education and development. The SAGE handbook of management learning, education and development, 42-68.

[3] Sterling, S. (2001). Sustainable Education: Re-Visioning Learning and Change. Schumacher Briefings. Schumacher UK, CREATE Environment Centre, Seaton Road, Bristol, BS1 6XN, England (6 pounds).

[4] Krueger Jr, N. F., Reilly, M. D., \& Carsrud, A. L. (2000). Competing models of entrepreneurial intentions. Journal of business venturing, 15(5-6), 411-432.

[5] Srikanthan, G., \& Dalrymple, J. (2005). Implementation of a holistic model for quality in higher education. Quality in Higher Education, 11(1), 69-81.

[6] Kember, D., Leung, D. Y., \& Ma, R. S. (2007). Characterizing learning environments capable of nurturing generic capabilities in higher education. Research in Higher Education, 48(5), 609. 
[7] PWC report on, "Redefining Higher Education for Inclusive Development in Eastern India", Indian Chamber of Commerce, 2010.

[8] Uttara Dukkipati, "Higher Education in India: sustaining long term growth" South Asia Monitor, 141, 01 May, 2010.

[9] Debkumar Mukherjee, "Higher Education in India-concerns and strategies" Asia-Pacific Business and Technology report 2010. Suggestions for improving quality of higher education

[10] Singh, J. D. (2011). Higher education in India-Issues, challenges and suggestions. Higher Education, 93103.

[11] Gupta, D., \& Gupta, N. (2012). Higher education in India: structure, statistics and challenges. Journal of education and Practice, 3(2).

[12] Hagvall Svensson, O., Lundqvist, M., \& Williams Middleton, K. (2017). Transformative, Transactional and Transmissive Modes of Teaching in Action-based Entrepreneurial Education. In ECSB Entrepreneurship Education (3E) Conference, May 10-12 Cork Ireland (pp. 1-15). 